\title{
The ICOMOS methodology for conservation of cultural heritage buildings: concepts, research and application to case studies
}

\author{
P. B. Lourenço \\ ISISE, University of Minho, Department of Civil Engineering, Guimarães, Portugal
}

doi: 10 14575/gl/rehab2014/095

\begin{abstract}
Modern societies understand built cultural heritage as a landmark of culture and diversity. Only during the last decades the idea that ancient buildings could be conserved and reused became appealing. Still, a large part of this heritage is affected by structural problems which menace the safety of buildings and people. The developments in the areas of inspection, non-destructive testing, monitoring and structural analysis of historical constructions, together with recent guidelines for reuse and conservation, allow for safer, economical and more adequate remedial measures. The paper addresses the issues of the methodology to adopt for the fabric of historic buildings, of the recent research and of some research needs, and of different cases studies
\end{abstract}

\section{INTRODUCTION}

The importance of ancient buildings has been for long exclusively attributed to their use, meaning that successive changes were made to fulfill their new function. At such times, lack of use would condemn the building to a ruin and, often, re-use of the stones elsewhere. Presently, modern societies understand built cultural heritage as a landmark of culture and diversity, which should last forever, being the task of the current generation to deliver the heritage in good shape for the generations to come. This act of culture poses high demands to engineers because deterioration is intrinsic to life (as an example the expected life of a modern building is fifty years).

Only during the last decades the idea that old and ancient buildings could be conserved and reused became appealing for the market. The present policy is not only to preserve but also to make buildings and the whole historic part of the cities alive, functioning and appealing to the inhabitants and to the tourists. It is the unique atmosphere of narrow streets and historic squares that provides a meaning to the cultural heritage of city centers, which must be the everyday reality for the local population.

Due to the effects of aggressive environment (earthquakes, soil settlements, traffic vibrations, air pollution, microclimate, etc.) and to the fact that many old buildings and historic centers were not subjected to maintenance, now a large part of this heritage is affected by structural problems which menace the safety of buildings and people. European countries have developed throughout the years a valuable experience and knowledge in the field of conservation, e.g. 
(Croci, 1998) or (Theodossopoulos, 2012). In recent years, large investments have been concentrated in this field, leading to impressive developments in the areas of inspection and nondestructive testing, e.g. (McCann \& Forde, 2001), monitoring, e.g. (Sohn et al., 2004) and structural analysis of historical constructions, e.g. (Lourenço, 2002). These developments, and recent guidelines for reuse and conservation, allow for safer, economical and more adequate remedial measures. These guidelines and their application to selected case studies are briefly revised next.

\section{ICOMOS RECOMMENDATIONS}

Structures in cultural heritage buildings, by their very nature and history (material and assembly), present a number of challenges in conservation, diagnosis, analysis, monitoring and strengthening that limit the application of modern legal codes and building standards. Recommendations are desirable and necessary to ensure rational methods of analysis and repair methods appropriate to the cultural context. Therefore, an international committee has prepared recommendations, intended to be useful to those involved in conservation problems (ICOMOS, 2003). In the particular case of seismic hazard, recent guidelines are detailed in (Cecchi \& Calvi, 2011). The ICOMOS recommendations contain Principles, where the basic concepts of conservation are presented, and Guidelines, where the rules and methodology that a designer should follow are discussed.

The principles entail: General criteria; Research and diagnosis; and Remedial measures and controls. A multi-disciplinary approach is obviously required and the peculiarity of heritage structures, with their complex history, requires the organization of studies and analysis in steps that are similar to those used in medicine. Anamnesis, diagnosis, therapy and controls, corresponding respectively to the condition survey, identification of the causes of damage and decay, choice of the remedial measures and control of the efficiency of the interventions. Thus, no action should be undertaken without ascertaining the likely benefit and harm to cultural heritage buildings. A full understanding of the structural behavior and material characteristics is essential for any project in cultural heritage buildings. Diagnosis is based on qualitative and quantitative approaches. The qualitative approach is based on direct observation of the structural damage and material decay as well as historical and archaeological research, while the quantitative approach requires material and structural tests, monitoring and structural analysis. Often the application of the same safety levels used in the design of new buildings requires excessive, if not impossible, measures. In these cases other methods, appropriately justified, may allow different approaches to safety. Therapy should address root causes rather than symptoms. Each intervention should be in proportion to the safety objectives, keeping intervention to the minimum necessary to guarantee safety and durability and with the least damage to heritage values. The choice between "traditional" and "innovative" techniques should be determined on a case-bycase basis with preference given to those that are least invasive and most compatible with heritage values, consistent with the need for safety and durability. At times the difficulty of evaluating both the safety levels and the possible benefits of interventions may suggest "an observational method", i.e. an incremental approach, beginning with a minimum level of intervention, with the possible adoption of subsequent supplementary or corrective measures. The characteristics of materials used in conservation work (in particular new materials) and their compatibility with existing materials should be fully established. This must include long-term effects, so that undesirable side effects are avoided.

A combination of scientific and cultural knowledge and experience is indispensable for the study of cultural heritage buildings. The purpose of all studies, research and interventions is to safeguard the cultural and historical value of the building as a whole and structural engineering provides scientific support necessary to obtain this result. The evaluation of a building frequently requires a holistic approach considering the building as a whole rather than just the assessment of individual elements. The investigation of the structure requires an interdisciplinary approach that goes beyond simple technical considerations because historical research can

discover phenomena involving structural behavior while historical questions may be answered by considering structural behavior. Knowledge of the structure requires information on its con- 
ception, on its constructional techniques, on the processes of decay and damage, on changes that have been made and finally on its present state.

In general the process towards the definition of remedial measures should include the following steps: (a) Acquisition of data: Information and investigation; (b) Historical, structural and architectural investigations; (c) Survey of the structure; (d) Field research and laboratory testing; (e) Monitoring, see Figure 1. Diagnosis and safety evaluation of the structure are two consecutive and related stages on the basis of which the effective need for and extent of treatment measures are determined. If these stages are performed incorrectly, the resulting decisions will be arbitrary: poor judgment may result in either conservative and therefore heavy-handed conservation measures or inadequate safety levels. Any assessment of safety is seriously affected by the uncertainty attached to data (actions, resistance, deformations, etc.), models, assumptions, etc. used in the research, and by the difficulty of representing real phenomena in a precise way.

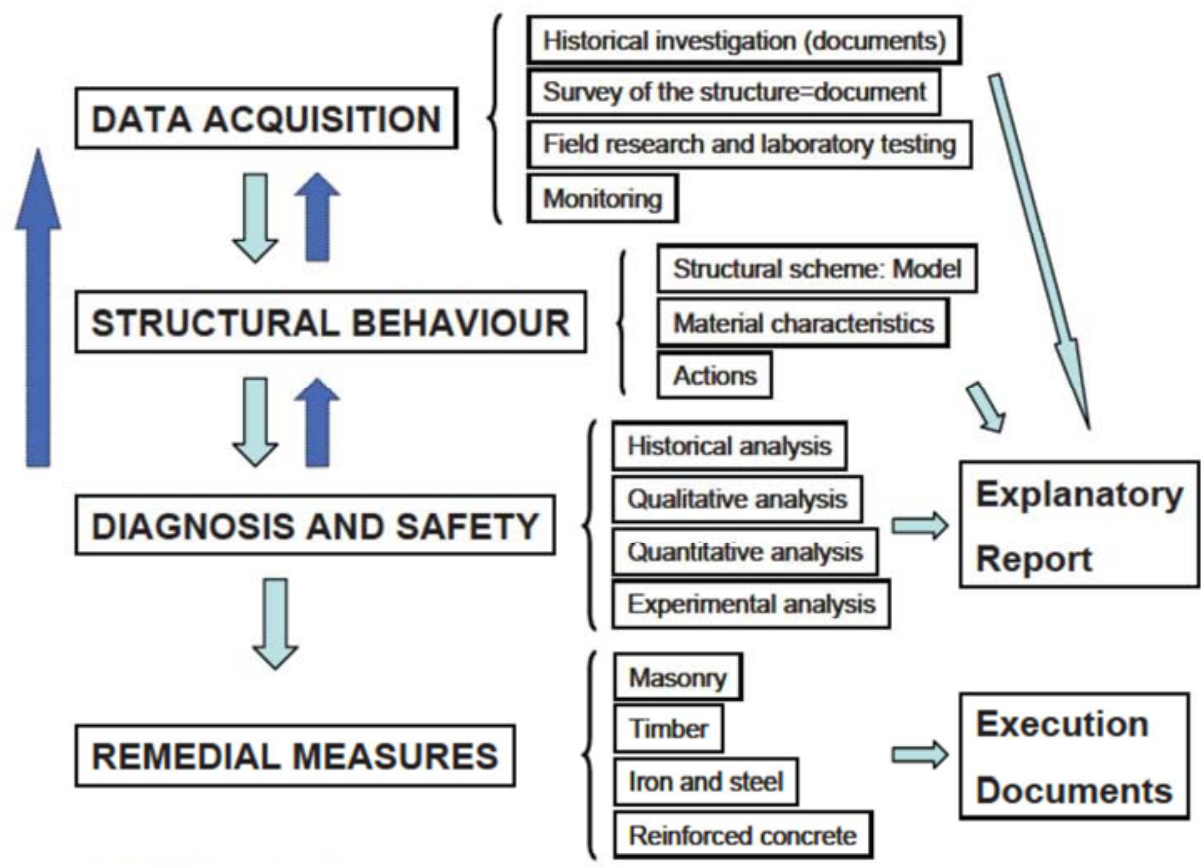

Figure 1. ICOMOS methodology.

The proposed methodology is in opposition with the past understanding, in which "conservation" was usually warranted by the powerfulness of the intervention, blind confidence existed in modern materials and technologies, a mistrust was present towards original or ancient materials and original resisting resources of the building, the value of original / ancient structure and structural principles was not recognized, the importance of previous studies was not fully recognize and significant negative experience accumulated, see Figure $2 \mathrm{a}$. The modern understanding is to respect the authenticity of the structure and structural principles governing its response, to believe that conservation should lie on knowledge and understanding of the nature of the structure and real causes of possible damage or alterations, to adopt respectful interventions (minimal, non-intrusive and reversible), to give importance to knowledge (comprising historical, material and structural aspects) and to assume that studies prior to intervention and the intervention are multidisciplinary tasks requiring the cooperation of historians, architects, engineers, physicists, among others, see Figure $2 \mathrm{~b}$. These aspects are further discussed below. 


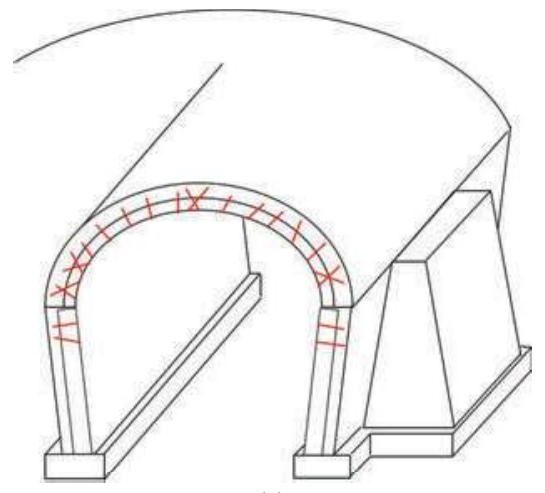

(a)

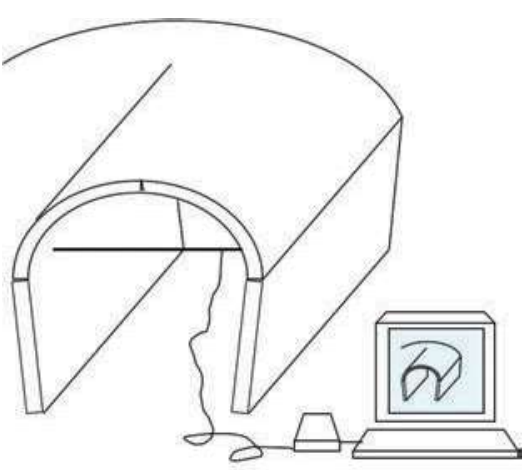

(b)

Figure 2. Two approaches in conservation: (a) past understanding; (b) present understanding.

\subsection{Diagnosis}

The phases of the study include "diagnosis" and "safety evaluation" of the structure, which are two consecutive and related stages on the basis of which the effective need for and extent of treatment measures are determined with the "design of remedial measures". As addressed above, if these two early stages are performed incorrectly, the resulting decisions will be arbitrary: poor judgment may result in either conservative and therefore heavy-handed conservation measures or inadequate safety levels. Diagnosis means to "identify causes of damage and decay". Safety evaluation means to "determine acceptability of safety levels by analyzing the present condition of structure and materials". Finally, the design of remedial measures means to "lay-out repair or strengthening actions to ascertain the required safety".

For the "diagnosis", four elements of analysis are considered: historical investigation; inspection; monitoring; structural analysis. The first two elements are mostly qualitative, while the last two elements are mostly quantitative. The first two elements are mostly empirical, which means that they are obtained by observation, while the last element is based on hypotheses, which means that proper validation is required. These elements are the basis of a scientific method that provides conclusions on the condition of the building and optimal interventions. Note the definition of a scientific method by the Oxford English Dictionary, as a method of procedure that has characterized natural science since the $17^{\text {th }}$ century, consisting in systematic observation, measurement, and experiment, and the formulation, testing, and modification of hypotheses.

The historical investigation has the purposes of understanding the conception and the significance of the building, the techniques and the skills used in its construction, the subsequent changes in both the structure and its environment, any historical events that may have caused damage, and any damage, failures, reconstructions, additions, changes, restoration work, structural modifications, and changes of use that lead to the present condition. A strong difficulty is that historical documents were usually prepared for other purposes and may therefore include technical information which is incorrect and/or may omit or misrepresent key facts or events which are significant.

The inspection and survey of present condition include, firstly, the survey of the structure by direct observation to identify decay and damage, identify any ongoing environmental effects on the building and to decide whether or not there are immediate risks and therefore urgent measures to be undertaken. Secondly, also field research and laboratory testing should be carried out, aiming to identify the internal morphology, the properties of the materials (mechanical, physical, chemical), the stresses and deformations of the structure and the presence of any discontinuities within the structure. Non-destructive tests should be preferred. If additional tests are necessary, consider cost-benefit analysis (benefit in information and possibility of reduced structural intervention against the loss of culturally significant material). If possible, different methods should be used and the results should be compared.

The objective of monitoring is to acquire useful information at different stages of the study / intervention of a building, to carry out previous, long term, characterization of the response of 
the building, to survey auxiliary remedial actions, to survey the final strengthening actions during their implementation and the long-term survey of a strengthened construction. Monitoring is also often used to characterize the dynamic response of the building, which provides the identification of several features of the building.

Finally, structural analysis if based on a model which is usually a compromise between realism and cost. The structural model must take into consideration and simulate all the aspects influencing the structural response, including: geometry and morphology (structural form, internal composition, connections between the structural elements...); material properties; actions (mechanical, physical, chemical...); existing alterations and damage (cracks, constructional mistakes, disconnections, crushing, leanings...); the interaction of the structure with the soil (except in the cases where it is judged to be irrelevant). It must be clear that no model does represent the full reality, that models are needed to reduce reality to a limited number of hypothesis or concepts (and to work with them), that models are needed to predict responses from concepts or hypothesis, and that must be validated and have limited possibilities.

\subsection{Safety evaluation}

The challenge of safety evaluation is trying to comply with the principle of minimum intervention, while avoiding an unacceptable risk level for human life or the movable heritage. Large difficulties can be expected given the limited applicability of the available codes, which are prepared for the design of modern structures and often inappropriately applied to historic structures. Modern codes are based in calculation approaches which may fail to recognize the real structural behavior and safety condition of ancient constructions. The enforcement of seismic and geotechnical codes, can lead to drastic and often unnecessary measures that fail to take into account the real structural behavior. Moreover, there is considerable subjectivity and uncertainty in safety assessment, namely attached to the data used (actions, geometry, deformations, material properties...) and the difficulty of representing real phenomena in a precise way with an adequate mathematical model. The subjective aspects involved in the study and evaluation of a historic building may lead to conclusions of uncertain reliability.

There are also legal issues, as modern legal codes and professional codes of practice adopt a conservative approach involving the application of safety factors to take into account the various uncertainties. This is appropriate for new structures where safety can be increased with modest increases in member size and cost. However, such an approach is not appropriate in historic structures where requirements to improve the strength may lead to the loss of historic fabric or to changes in the original conception of the structure. A more flexible and broader approach, where calculations are not the only source of evaluation, needs to be adopted for historic structures to relate the remedial measures more clearly to the actual structural behavior and to retain the principle of minimum intervention. It must be clear, therefore, that the safety evaluation of an historic building cannot be exclusively based on the results of calculations because they can be unreliable and inappropriate.

The broader understanding of safety consists of combining different approaches, each giving a separate contribution. Their combination will produce the best possible 'verdict' based on the data available. Safety can incorporate a historical approach (Knowing from history, which is a full-scale / real time experiment. Knowing from the behavior shown by the same structure, or similar ones, in the occasion of historical actions), a qualitative approach (an inductive procedure that used comparison and extrapolation from other buildings), an analytical approach (the usual deductive procedure adopted for structural analysis, modelling and analyzing a structure to obtain quantitative predictions on the response subjected to different actions) and an experimental approach (tests on the entire building or individual components, possibly combined with monitoring).

\subsection{Conclusion}

Conservation of historic buildings adopts a scientific approach, combining different sources and approaches. The methodology is consistent, as it uses similar approaches for diagnosis, safety evaluation and design of intervention. Still, subjectivity is possible and importance is given to the personal judgment, recognizing the need for experts and the value of their personal opinion. 


\section{THE WORKS AT CATHEDRAL OF PORTO}

The foundation of the Cathedral of Porto is the middle of the $12^{\text {th }}$ century. For 800 years, the settlement was a repository of added parts. In a framework of a continuous construction yard, the main fabrics are: Romanesque and proto-gothic, gothic, renascence, mannerist, baroque, neoclassic, contemporary works from the first half of the 20th century and, finally, the present works. The governing thread of the program of the current intervention is to rehabilitate the previous restoration works, carried out in the first half of the 20th century, see (Lourenço et al., 2004) for details on the evolution of the complex and the basis for the conservations works carried out. The aim is to reactivate, rehabilitate and up-grade the competence, where competence is understood as the capacity to perform adequately, of the structures, the materials, the shapes and also the space, assumed as a support for functionality. The intervention in the building was organized around five operations: removal of infestations, consolidation, water-tightness, ventilation and protection. Here, only some of the structural works are briefly reviewed.

Figure 3 shows selected views of the compound of the Cathedral, which has dimensions about $60 \times 60 \mathrm{~m} 2$ in plan, with a maximum height of the towers about $35 \mathrm{~m}$. The compound includes the church, a gothic cloister on the south side, side chapels, a gallery on the north side, a sacristy, several chapels and other annexes. The church has a typical Latin cross, with three naves and five spans, and two rectangular towers facing west.

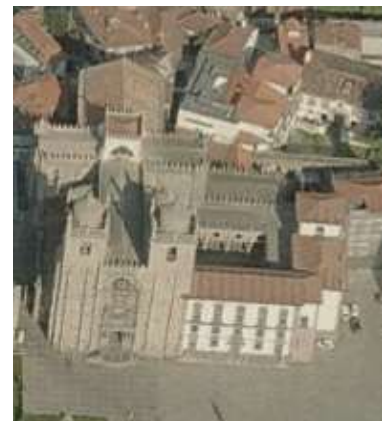

(a)

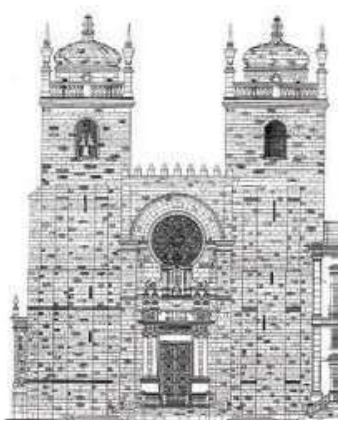

(b)

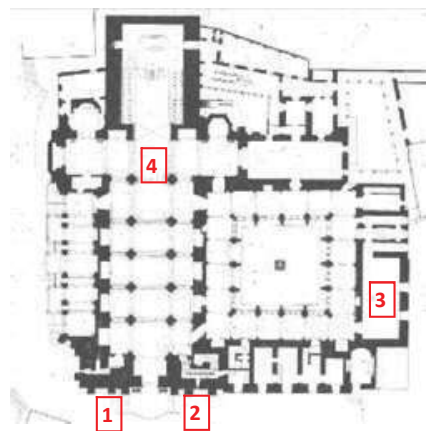

(c)

Figure 3. Aspect of the Cathedral: (a) Aerial View; (b) Façade; (c) Plan. Legend: 1 - North Tower; 2 South Tower; 3 - St. Vincent Chapel; 4 - Skylight.

\subsection{Remedial measures in the towers}

The cross section of the towers is approximately square with a side of $10.0 \mathrm{~m}$ and exhibits a variable thickness, with a minimum of $1.7 \mathrm{~m}$ at the base. The height of the towers is approximately $35 \mathrm{~m}$, which means that the average stress at the base is around $1.0 \mathrm{~N} / \mathrm{mm}^{2}$. This value is rather low for regular granite masonry but it is rather high for rubble masonry (with or without mortar joints). In the main façade, two buttresses are apparent in each tower, see Figure $3 b$. The structure suffered several major modifications through time, which resulted in a very complex internal structure with different load bearing internal elements at each level. The structure of the towers cannot be understood from structural reasons and several openings are closed, facing staircases or vaults. The entrance for the towers is located at mid-height, with a connection between both towers from the top of the main vault. But the two towers have a rather different structure. The North tower (presently with the bells and clock) features a horizontal mid-level with stone slabs and architraves apparently supported in columns and stone struts. The South tower possesses an internal core with a staircase shaped helicoidally. The constitution of the masonry walls from the towers was characterized using visual inspection, removing stones of the outer leave in the interior of the tower and by using a boroscopic camera inserted in cracks or in holes drilled in joints, see Figure 4. From the inspection, it was possible to conclude that the three-leaf walls have external leaves of granite ashlars with a thickness ranging from 0.30 to $0.70 \mathrm{~m}$, while the middle leave is made from loose smaller stones and silty soil. The combina- 
tion of heavy rain in Porto, strong winds in the top of the hill where the Cathedral is located, and the open joints in the external masonry face, results in a wet infill even in the summer and the continuous washing out of the infill.

The towers exhibit distributed cracking and significant out-of-plane movements. The existing damage resulted in the past addition of three iron ties (date unknown), see Figure 5. Tie T1 presents a severely deformed anchorage and tie T3 is corroded and broken. The separation between the East and West façades of the South tower continued after tie T3 was broken. The masonry walls in the vicinity of the anchorages are also deformed, as expected due to the application of a large point load. The South tower is more damaged than the North tower, with severe cracks and out-of-plumb walls. Separation between the internal and external leaves of the walls is confirmed by the longitudinal cracking observed in most of the openings, with a maximum width of some centimeters.
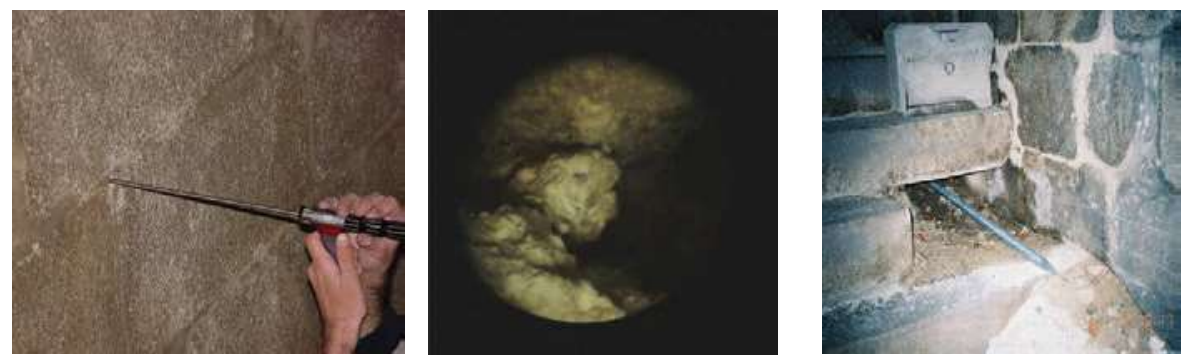

Figure 4. Visual inspection with boroscopic camera and inspection openings.

The solution adopted for strengthening consists mostly of a steel ring in both towers, aiming at confining the structure along the two orthogonal directions, in the sole location possible, see Figure 6a, b. The rings are made with welded stainless steel plates (class AISI 316L), connected to the towers using long, inclined stainless steel anchorages inside of a cloth duct to prevent generalized injection, see Figure 6c-e. The length of the steel profiles is defined so that the elements can be transported to the location through the existing doors and can be easily assembled in situ, without any further welding. In the North tower, the ring also aims at providing a support for the stone pavement for the bells, as stone columns are much deteriorated and had no structural function and the stone struts have very deficient conception. The steel ring is made of channel profiles $(240 \times 120 \mathrm{~mm}$ and $200 \times 100 \mathrm{~mm}$ height $)$. In the South tower, a set of two ties was provided to the ring, because it was possible for aesthetic reasons and they are a testimony of the ancient broken tie. The ring must cross the staircase at a selected location because the complex internal structure of the tower does not allow otherwise. Due to the lack of internal stiffening elements, a much stiffer steel frame is needed and the steel ring is made of $\mathrm{H}$ profiles $(180 \times 180 \mathrm{~mm})$. Due to the bulging outwards of the East and South façades, and the severe cracks in the corners, several short ties have been added to the structure to stitch the East and South façades, and two long ties through the core of the South façade have been added to connect the West and East façades, see Figure $6 \mathrm{f}$. Figure $6 \mathrm{~g}$ presents details of the two types of anchorage plates adopted (circular plates and specially designed crosses).
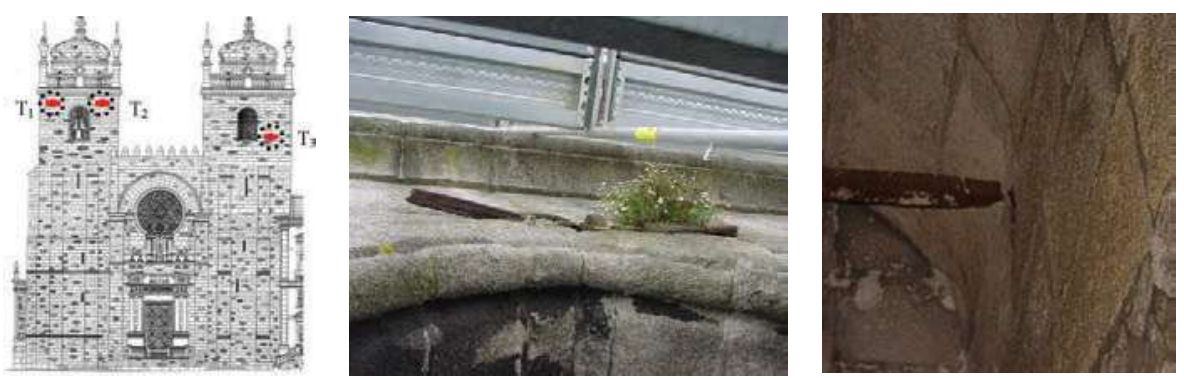

Figure 5. Ancient tower ties, with deformed anchorage (T1) and broken tie (T3). 
Given the cultural importance of the building and the significant damage in the South tower, a monitoring system was planned and installed. The system includes four waterproof crackmeters in the largest cracks, two strain gages for the new ties, two biaxial clinometers to measure the tilting of the tower, as well as temperature, humidity and wind sensors. The system includes also a GSM interface for remote monitoring. The measurements in the crackmeters (amplitudes lower than $0.3 \mathrm{~mm}$ ) and clinometers (amplitudes lower than $0.6 \mathrm{~mm} / \mathrm{m}$ ) are rather small and they follow the temperature measurements. The wind speed measured indicates that the direction of the gust wind is North / Northwest, with velocities up to $150 \mathrm{~km} / \mathrm{h}$. An auto regressive exogenous model indicates that the measurements of the cracks are of good quality and the variations are explained by the environmental effects and not by crack opening. A similar conclusion holds for the measurements of stresses in the steel ties. The values in the tiltmeters are low but a rotation seems to be observed in the South tower, around $0.01 \%$ year or $0.1 \%$ decade.

\subsection{Skylight in the transept}

The skylight is located above the transept and presents different cracks, which occurred after the works carried out in the first half of the $20^{\text {th }}$ century. In addition, infill material from the vault had recently fallen in the transept. The skylight is made of four walls supported in large arched windows opened in the $18^{\text {th }}$ century, with the exception of the East façade with exhibits no opening, see Figure $7 \mathrm{a}$. It has a square plan with $7.5 \mathrm{~m}$ side, walls with 6.5 height and $0.65 \mathrm{~m}$ thickness. The thickness is reduced to $0.4 \mathrm{~m}$ above the vaults and, again, to $0.2 \mathrm{~m}$ in the battlements. Buttresses can be found in each corner and a ribbed stone vault makes the ceiling, further topped by a timber double slope roof. The masonry in the walls is of very low quality, made of rubble stone and weak lime mortar. The openings form pointed arches, supported at the thirds of the span with T-shaped columns. The vault is made with stone slabs with a thickness between 0.14 and $0.54 \mathrm{~m}$. Rubble loose infill was removed on top of the vault (about $10 \mathrm{~m}^{3}$ ).

The three walls with windows are cracked at the arch key, with maximum crack widths of 10 , 1 and $<0.5 \mathrm{~mm}$, in the façades West, North and South, respectively. These walls are also bulging outwards. Figure $7 \mathrm{~b}$ shows the main crack in the West façade, which crosses the entire section of the wall. Smaller cracks can be also observed closer to the buttresses, under the opening, together with horizontal cracks in the window columns due to bending. The most severe crack in the interior has a width of $25 \mathrm{~mm}$ and shows that the vault is separated from the wall in the West façade. Due to this crack, the stone slabs of the vault are no longer supported in the side rib and a settlement of about $20 \mathrm{~mm}$ can be observed at the key if the vault.

The observation of the damage in the skylight, together with the local relief, the severe separation between the East façade and the chancel, the old documents indicating consolidation and enlargement of foundations and the bulging of the walls of the nave indicate that soil settlements and weak foundations can be the main cause of damage. A finite element model of the skylight was used to understand and justify the existing damage. The actions considered include the self-weight of the structure, the weight of the infill, the seismic action and differential temperature. The results for the combination of self-weight plus rubble infill provided a maximum tensile stress found lower than $0.1 \mathrm{~N} / \mathrm{mm}^{2}$ and located in the window-sills and ribs. The skylight should have minor or no damage under self-weight and infill. Seismic loading and temperature were then added to the structure, aiming at explaining the damage, see Figure 8a, b. Even if the deformation for seismic loading has some resemblance with the observed movements in the structure, the stresses found are too low to provoke any damage. The deformed mesh associated with the differential temperature indicates that the walls move to the exterior and suffer significant bending, with significant curvatures in the columns. Still moderate stresses are found and the deformation is not in agreement with the observed movements, meaning that the temperature effect is relevant but should not be the main cause of the damage. A full model of the church was then prepared to analyze the influence between the skylight, the adjacent structure and the soil, see Figure $8 \mathrm{~b}$. Very high tensile stresses are found in the skylight and the deformation is similar to the one observed in the structure, confirming that this is the major cause of damage. The remedial measures are given in Lourenço et al. (2004). 


\section{FINAL NOTE}

Conservation engineering is a new, complex and exciting field, which requires specific education. Engineers are still educated today much in the same way as they were educated decades ago, oriented to new construction, even if there are currently clear methodologies to address the conservation of existing structures in general, and cultural heritage buildings in particular. A scientific methodology with a sound basis is available, but experience and personal judgment remain a key issue.

One case study has been presented for a masonry building. Masonry is a material used in construction for over 10,000 years, usually a very durable material. The case study required structural repair, due to ageing, settlements and alterations, which provoked a loss of capacity. The case study illustrates the need to clearly understand the behavior of complex structures, to adequately assess the need of structural strengthening and to analyze the cost of possible solutions at an early design phase.

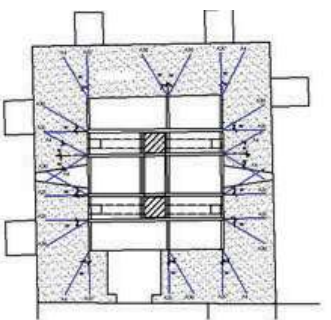

(a)

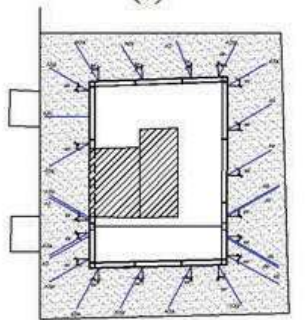

(b)

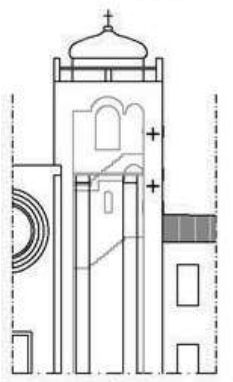

(f)

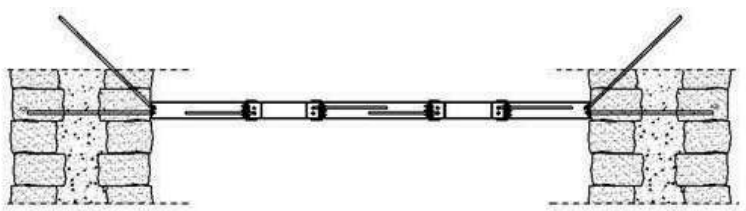

(c)

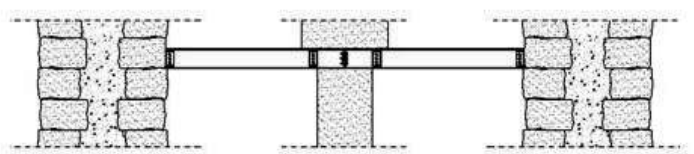

(d)

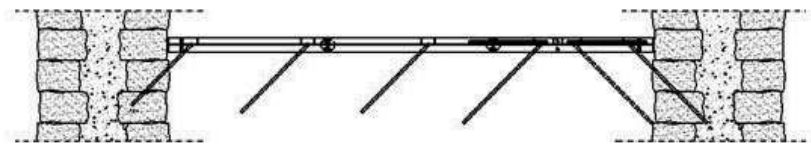

(e)
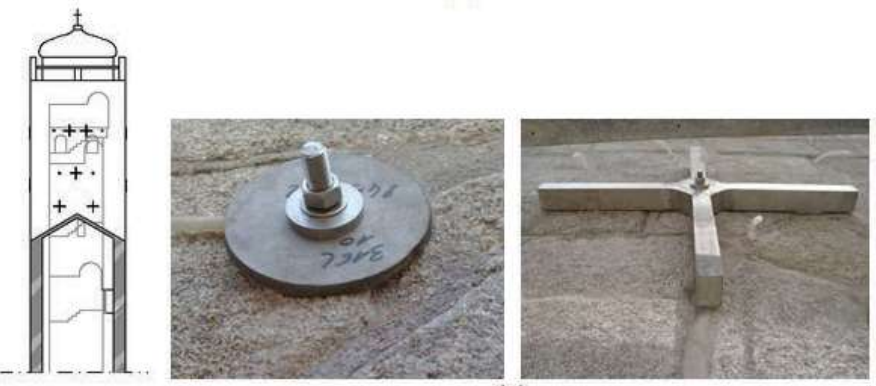

(g)

Figure 6. Aspect of the strengthening of the towers: (a) Ring for the north tower; (b) Ring for the south tower; (c) North-south section for north tower; (d) West-east section for north tower; (e) Typical section for south tower; (f) Additional ties in the west and south façades of the south tower; (g) Details of the anchorage plates. 


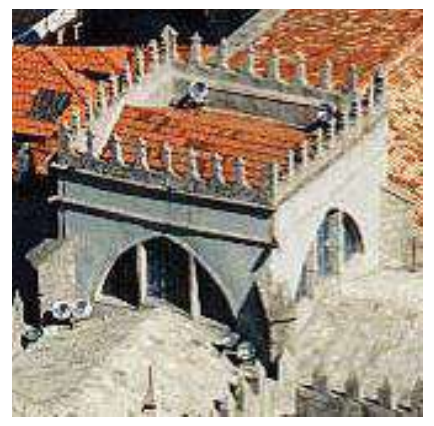

(a)

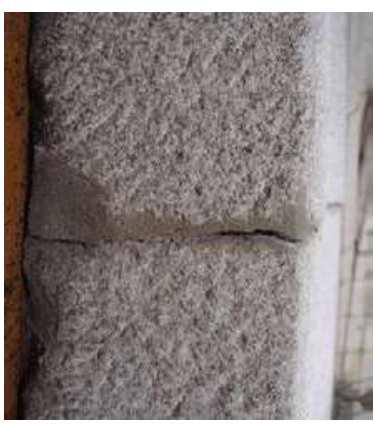

(b)

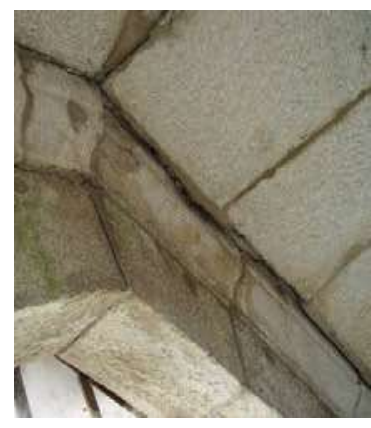

vaults

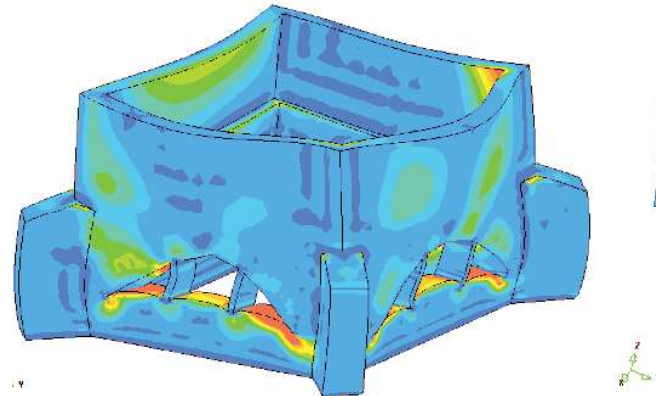

(a)

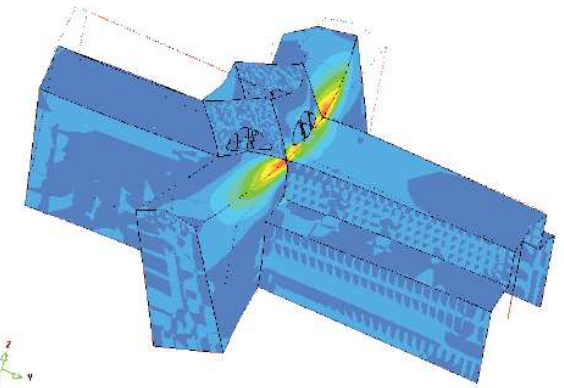

(b)

Figure 8. FEM analysis: (a) Live loads; (b) Dead load for full model.

\section{REFERENCES}

Cecchi, R. \& Calvi, M. 2011. Guidelines for evaluation and mitigation of seismic risk to cultural heritage. Roma: Gangemi.

Croci, G. 1998. The conservation and structural restoration of architectural heritage. Southampton: WIT Press.

ICOMOS. 2003. Recommendations for the analysis, conservation and structural restoration of architectural heritage.

Lourenço, P. B. 2002. Computations on historic masonry structures. Progress in Structural Engineering and Materials 4(3): 301-319.

Lourenço, P. B., Melo, A. \& Carneiro, M. 2004. Remedial measures for Cathedral of Porto: A postmodern conservation approach. In C. Modena, P. B. Lourenço and P. Roca (ed.), Structural analysis of historical constructions IV: 51-62. Leiden: A. A. Balkema Publishers.

McCann, D. M. \& Forde, M. C. 2001. Review of NDT methods in the assessment of concrete and masonry structures. NDT \& E International 34 (2): 71-84.

Sohn, H., Farrar. C. R., Hemez, F. M, Shunk, D. D., Stinemates, D. W., Nadler, B. R. \& Czarnecki, J. J. 2004. A review of structural health monitoring literature: 1996-2001. Los Alamos, New Mexico: Los Alamos National Laboratory.

Theodossopoulos, D. 2012. Structural design in building conservation. Oxon: Routledge. 